Int. J. Mater. Res. (formerly Z. Metallkd.) 110 (2019) 4; page 351- 358

\title{
Effect of heat treatment on apatite coatings deposited on pre-calcified titanium substrates.
}

Ana M. Beltrán ${ }^{\mathrm{a},{ }^{*}}$, Yaimi Martin-Santana ${ }^{\mathrm{b}}$, Jesús E. González ${ }^{\mathrm{b}}$, Isabel Montealegre-Meléndez ${ }^{\mathrm{a}}$, Eduardo González ${ }^{\mathrm{b}}$, Eduardo Peón-Avés ${ }^{\mathrm{b}}$, Francisco J. Gotor ${ }^{\mathrm{c}}$, Yadir Torres ${ }^{\mathrm{a}}$

${ }^{a}$ Departamento de Ingeniería y Ciencia de los Materiales y el Transporte, Universidad de Sevilla, Seville, Spain.

${ }^{\mathrm{b}}$ Department of Ceramic and Metallic Biomaterials, Biomaterials Center, University of Havana, Cuba.

${ }^{\mathrm{c}}$ Materials Science Institute of Seville (CSIC-US), Seville, Spain.

Titanium and its alloys are considered interesting materials for endosseous implants. However, they still present drawbacks related to their in-vivo behavior that can be overcome by coatings, such as apatite. This work focuses on the deposition of apatite coatings on commercial pure titanium (grade II) substrates previously pre-calcified. The influence of the temperature used in the thermal treatment on the microstructure and tribo-mechanical surface properties was analyzed. The coatings were structurally and chemically characterized and their tribomechanical behavior was evaluated. The nano-apatite coatings were only formed on surfaces with successively treatments in $\mathrm{NaOH}$ and $\mathrm{CaCl}_{2}$ solutions. In addition, the scratch tests showed that after the heat treatment the nano-apatite coatings had high bond strength to the substrate.

Keywords: Pre-calcified substrates; hydroxyapatite coatings; thermal treatments; tribomechanical characterization. 


\section{Introduction}

Medical advances in bone and/or tissues replacement are limited for the reduced number of materials available for such applications. Such materials have to show properties comparable to bones [1,2]. Usually, the clinical success of an implant is directly related to its proper osseointegration behavior [3], which strongly depends on the physical and chemical properties of its surface because they determine the adhesion, proliferation and differentiation of bone-forming cells $[4,5]$.

Nowadays, commercially pure Titanium (cp-Ti) and Titanium (Ti) alloys are considered attractive materials for biomedical applications thank to their appropriate mechanical properties, good corrosion resistance and biocompatibility [6-10]. However, biomechanical failure are possible due to the high Young's modulus mismatch between the implant and the bone tissue $[11,12]$. In addition, a long implantation time is generally required for achieving the osseointegration of Ti-based implants [13]. In order to improve the surface properties and promoting the osseointegration, different superficial modification treatments, which transform the roughness, the texture and/or the chemical composition of the implants' surfaces, have been proposed [14-17]. These treatments can increase bioactivity, active the surface, enable coating deposition, improve the corrosion resistance and inhibit microorganism growth.

Cp-Ti and Ti-based alloys surfaces can be modified by physical, chemical and electrochemical processes $[14,18,19]$. They lead to modifications of the roughness, topography, elemental and phase composition, making also possible the deposition of calcium-phosphate coatings by wet chemical treatment methods. The use of different coatings, such as oxides, hydroxides, titanates and calcium phosphate, has been already described [5,20,21]. Among them, apatite is frequently used because it is the main inorganic component of bones and presents similar properties [22]. Furthermore, calcium phosphate (Ca-P) coatings are commonly employed to improve the surface bioactivity and, therefore, the osseointegration of the implants. Several methods have been developed for the deposition of Ca-P coatings [19,23]. Nowadays, the use of wet chemical treatment methods have been reported by different researchers $[24,25]$. However, there are still some limits, especially related to the low coating-substrate bond strength [26-29] that must be solved.

In this framework, this research is focused on the study of the deposition of apatite coatings on cp-Ti (grade II) substrates by precipitation methods. Furthermore, the influence of 
pre-calcification and heat treatments on the morphology, the chemical and phase composition, and the tribo-mechanical properties of the apatite coatings were evaluated.

\section{Experimental Procedure}

\subsection{Description of samples}

Cp-Ti grade II substrates $(20 \times 5 \times 1 \mathrm{~mm})$ were prepared. Frstly they were polished employing $\mathrm{SiC}$ sandpapers (grid numbers 280 and 400$)$; next acid etched was used $\left(67 \% \mathrm{H}_{2} \mathrm{SO}_{4}\right.$ and $\mathrm{HCl}$, $\mathrm{V} / \mathrm{V}: 1: 1)$ at $80^{\circ} \mathrm{C}$ for 20 minutes, after that they were cleaned with distilled water and dried at $90{ }^{\circ} \mathrm{C}$ for one hour (AE treatment). In a second stage, two pre-calcification treatments were tested. On the one hand, some of the substrates were treated in a saturated $\mathrm{Ca}(\mathrm{OH})_{2}$ solution at $100{ }^{\circ} \mathrm{C}$ for one hour; following, they were rinsed employing distilled water and then, they were dried at $90^{\circ} \mathrm{C}$ for 30 minutes (CT treatment). On the other hand, other group of substrates was successively treated in $\mathrm{NaOH}$ and $\mathrm{CaCl}_{2}$ solutions $(10 \mathrm{~mol} / \mathrm{l} \mathrm{NaOH}$ and $1 \mathrm{~mol} / \mathrm{l} \mathrm{CaCl}$ ). The specimens were firstly treated by $\mathrm{NaOH}$ solution at $60^{\circ} \mathrm{C}$ during 24 hours, following by rinsing and then the specimens were dried. After this stage, the specimens were immersed in $\mathrm{CaCl}_{2}$ solution at $40{ }^{\circ} \mathrm{C}$ during 24 hours. Concluding with this second treatment process, the specimens were thorough cleaned with distilled water and they were dried at $90{ }^{\circ} \mathrm{C}$ for one hour (NT treatment).

The apatite coatings were deposited on the cp-Ti samples in a supersaturate calcium solution (SCS). In $500 \mathrm{ml}$ distilled water, the reagent grade $\mathrm{CaCl}_{2}(0.9713 \mathrm{~g}), \mathrm{NaH}_{2} \mathrm{PO}_{4}(0.2625 \mathrm{~g})$ and $\mathrm{NaHCO}_{3}(0.1278 \mathrm{~g})$ were successively dissolved. The calcium ion concentrations tested were equal to a simulated body fluid (SBF x 7) [30]. The pre-calcified samples were treated in the SCS at $36.5^{\circ} \mathrm{C}$ during 4 hours, with a stirring rate of $100 \mathrm{rpm}$. After that, the samples were rinsed with distilled water. On the final stage, all the samples were thermal treated. Two temperature were used, $600{ }^{\circ} \mathrm{C}$ or $800{ }^{\circ} \mathrm{C}$, setting time for one hour in order to compare the effect of the temperature. Table 1 summarizes the description of the treated samples.

\subsection{Characterization techniques}

The surface of the samples was characterized by scanning electron microscopy (SEM) using an S-4800 field emission gun microscope (Hitachi, Japan). SEM images were analyzed using the free software Image $\mathbf{J}$ to determine the size of the pores and particles. The semi-quantitative elemental composition was determined using X-ray energy dispersive spectroscopy (XEDS) 
coupled to SEM (Quantax EDS, Bruker Corporation, Germany). X-ray diffraction (XRD) analysis was performed in a Panalytical X'Pert Pro instrument (Panalytical, Almelo, The Netherlands) equipped with a $\theta / \theta$ goniometer, a $\mathrm{Cu} \mathrm{K} \alpha$ radiation source (40 kV, $40 \mathrm{~mA})$, a secondary $\mathrm{K} \beta$ filter and an $\mathrm{X}^{\prime}$ Celerator detector. The diffraction patterns were scanned from $20^{\circ}$ to $90^{\circ}(2 \theta)$ in a step-scan mode at a step size of $0.05^{\circ}$ and a counting time of $300 \mathrm{~s} / \mathrm{step}$.

Conventional surface roughness of the modified surfaces was tested by Surftest SJ-210 (Mitutoyo, Japan) at $0.5 \mathrm{~mm} / \mathrm{s}$. These measures were carried out at least in two replica of each sample and data were acquired five times on each surface. The tribo-mechanical properties were measured by scratch tests performed in a MICROTEST commercial device (MTR3/50-50/NI) using a Rockwell diamond tip with a diameter of $200 \mu \mathrm{m}$ and constant load of $5 \mathrm{~N}$ at a rate of $0.5 \mathrm{~mm} / \mathrm{min}$ for $4 \mathrm{~mm}$ length [31]. The normal load was continuously recorded during scratching. Results were given as scratch penetration-load curves. For each sample, the real plastic deformation (deformation after scratching) and the elastic recovery (difference in depth between the scratch and post-scan curves) were measured. However, before the scratch test, the sample was scanned to evaluate the roughness profile of the surface. From this test, different roughness parameters were determined: the arithmetic average of the absolute values of all points of the profile (Ra), the root mean square of the values of all points of the profile $(\mathrm{Rq})$, the maximum peak-to-valley height of the entire measurement trace (Ry) and the arithmetic average of the maximum peak-to-valley height of the roughness values of five consecutive sampling sections over the filtered profile $(\mathrm{Rz})$.

The experimental results were processed by Statgraphics Centurion XV Software (Statpoint Technologies, Inc., USA), using a multi-samples comparison test (Multiple Range Tests) with an analysis of variance (ANOVA) test. A value of $\mathrm{P}<0.05$ was used to consider a difference as statistically significant.

\section{Results}

\subsection{Surface modification treatments}

Figure 1a shows a SEM image of the cp-Ti surface after the polished process; it reveals a topography of valleys and peaks aligned along the direction of the abrasive particles from the sandpaper. However, the surface of the acid etched samples (Fig. 1b) did not present these valleys and peaks, it is a new highly porous topography, formed by micro-pores (average size $4.1 \pm 1.7 \mu \mathrm{m}$ ) with irregular shape was observed. In general, after the acid etching, the samples 
presented the surface roughness $(R a)$ of $1.1 \pm 0.1 \mu \mathrm{m}$. Treatment in aqueous $\mathrm{Ca}(\mathrm{OH})_{2}$ solution (labelled CT) did not generate important changes on the morphology of the acid etched surfaces (Fig. 1c), although it affected to the pores sizes. These surfaces showed an average size of pores of $2.9 \pm 0.4 \mu \mathrm{m}$. Moreover, samples successively treated in aqueous $\mathrm{NaOH}$ and $\mathrm{CaCl}_{2}$ solutions (labelled NT) presented porous surfaces, with pores of different sizes (micro and nano topography, not shown in this work) and globular structures (Fig. 1d). These surfaces had an average pore size of $3.2 \pm 1.3 \mu \mathrm{m}$. The SEM images also displayed micro-cracks on these surfaces, which is typical of Ti-surfaces treated in alkaline solutions [32]. Additionally, the surfaces of the specimens named $\mathrm{CT}$ (in aqueous $\mathrm{Ca}(\mathrm{OH})_{2}$ ) and $\mathrm{NT}$ (in aqueous $\mathrm{NaOH}$ ) presented surface roughness $(R a)$ of $1.21 \pm 0.36$ and $1.33 \pm 0.37 \mu \mathrm{m}$, respectively.

Semi-quantitative elemental analysis of the treated samples by XEDS-SEM showed the presence of Ti peaks in all surfaces (Fig. 2 and Table 2). The presence of $\mathrm{Ca}$ and $\mathrm{O}$ peaks was only detected in those pre-calcified samples that were successively treated in $\mathrm{NaOH}$ and $\mathrm{CaCl}_{2}$ solutions.

\subsection{Apatite coatings}

Figure 3 shows SEM images of the pre-calcified cp-Ti surfaces after the SCS treatment (inset: higher magnification images of each surface). These images showed the formation of apatite layers only on NT600 and NT800 (named specimens in aqueous NaOH and heat treatment at $600^{\circ} \mathrm{C}$ and $800^{\circ} \mathrm{C}$ ) surfaces. The elemental composition of the surfaces was analyzed by semiquantitative XEDS-SEM analyses (Fig. 4). Values are summarize in Table 2. While O was detected in the four samples (CT and NT at $600{ }^{\circ} \mathrm{C}$ and $800{ }^{\circ} \mathrm{C}$ heat-treated), $\mathrm{Ca}$ and $\mathrm{P}$ peaks were only observed on the NT600 and NT800 surfaces, in which the formation of the apatite coating could be appreciated.

Figure 5a-5d shows the XRD patterns of the four studied surfaces. Peaks corresponding to the hydroxyapatite were only detected on samples NT600 and NT800, confirming the XEDS-SEM results. In addition, the main peak of the Rutile phase was observed at $27.5^{\circ}$ ( 2 Theta) in the specimens CT600, CT800 and NT800. Additionally, other peaks of this oxide appeared in the patterns of samples processed at $800{ }^{\circ} \mathrm{C}$ (CT800 and NT800), indicating a higher oxidation extent of the titanium substrate.

Concerning the tribo-mechanical studies, measurements of roughness and scratch tests were performed. Surface roughness profiles are displayed in Fig. 6. Moreover, the related parameters, 
in absolute values, are summarized in Table 3. All data are expressed as mean values; relative error is below $0.1 \%$ for all the measures. For similar treatments, CT or NT, values of Ra and Ry are comparable and they were larger for higher temperatures, it means in samples CT800 and NT800.

Figure 7 shows the difference between the in situ penetration (plastic and elastic deformation) (solid curves) and the real plastic deformation (penetration depth) associated to the scratch tests (dotted curves). Average values for the in situ penetration depth $\left(\mathrm{P}_{\mathrm{d}}\right)$, permanent plastic deformation $\left(\mathrm{P}_{1}\right)$ and elastic recovery $\left(\varepsilon_{\mathrm{r}}\right)$ are summarized in Table 4.

Figure 8a - d shows the SEM images of the scar (or track) scratch on the four surfaces (inset: higher magnification images of the scar). The low critical load value $\left(\mathrm{L}_{\mathrm{C} 1}\right)$ in the samples CT600, NT600 and NT800 were higher than 5 N, while the samples CT800 failed to this load. A preliminary analysis of the feature inside of the groove scratch and rounded regions indicates the presence of plastic deformation of the titanium substrate, as well as chipping and buckling spallation of the coating (layer affected by surface treatment). The observed features suggest a failure mechanism, mainly adhesive type (commonly under compression stress behind the stylus). For hard and brittle coating on ductile substrates, substrate deformation can occur before delamination or chipping failure. These facts may increase with coating thickness and hardness. In this context, the sample CT800 had an irregular shape, which was related to multiple globular structures protuberances on this surface.

\section{Discussion}

In this work, two different pre-calcification treatments (CT and NT) were tested before the deposition of the apatite coatings on cp-Ti substrates. Additionally, the effects of the possible formed layers were evaluated as influence factor on the mechanical properties. Both treatments caused significant changes in the topographies of the pre-calcified surfaces in comparison with the polished and acid etched surfaces. Furthermore, the surfaces obtained after these treatments showed remarkable differences of the pore size. Specifically, a micro-nanoscale topography was observed on the surfaces after the NT pre-calcification treatment (not shown in this work). In general, this topography is similar to the reported for titanium surfaces treated in $\mathrm{NaOH}$ solutions (micro/nano-network structured). Besides, the XEDS spectra of these samples did not show the presence of $\mathrm{Na}$ peaks, although $\mathrm{Ca}$ peaks were observed. The absence of $\mathrm{Na}$ on the surface of NT samples must be related to the fact that this element was replaced by Ca during 
the treatment in the $\mathrm{CaCl}_{2}$ solution. According to Kisuki et al. [18], during $\mathrm{NaOH}$ treatment, a sodium hydrogen titanate $\left(\mathrm{Na}_{2} \mathrm{H}_{2 \mathrm{x}} \mathrm{Ti}_{3} \mathrm{O}_{7 \mathrm{n}} \mathrm{H}_{2} \mathrm{O}\right)$ is formed on the titanium surface; in this compound, $\mathrm{Na}^{+}$ions are easily replaced by $\mathrm{Ca}^{2+}$ ions on $\mathrm{CaCl}_{2}$ treatment. The formation of calcium compounds on the titanium surface is an important factor owing to its influence on the subsequent coating deposition [26], since they contribute to the nucleation of apatite structures and, therefore, it reduces the required time to obtain the desired layer thickness.

Besides, two different temperatures $\left(600{ }^{\circ} \mathrm{C}\right.$ and $\left.800{ }^{\circ} \mathrm{C}\right)$ were employed during the heat treatment of the samples treated in SCS solution to investigate the effects on the morphology and the tribo-mechanical properties of surfaces. Significant changes were also observed in the topography of both surfaces compared to the pre-calcified samples. Higher magnification SEM image of sample CT800 (inset Fig. 3c) displays rod-like structures, which should be related to the presence of rutile on the surfaces, as confirmed by XRD (Fig. 5). This particular microstructure has already been reported on titanium surfaces treated with $\mathrm{NaOH}$ solutions and subsequently annealed at $700-900{ }^{\circ} \mathrm{C}[33,34]$.

Figure 3a and c did not clearly reveal the formation of apatite layers on the CT600 and CT800 surfaces. However, significant changes in their topographies and morphologies were observed in comparison with the pre-calcified surfaces by the CT treatment. The micro-pores generated by the acid etching were not appreciated in CT800 surfaces, while at higher magnifications, rod-like shape structures were observed on these surfaces. In addition, CT600 surfaces showed a different topography that CT800 surfaces. XRD analyses performed on CT600 and CT800 surfaces confirmed the lack of the hydroxyapatite coating on these samples, as also shown from the XEDS results.

In the case of NT600 and NT800 samples, significant changes were detected on their topography compared to CT600 and CT800 samples (Fig. 3a-d). It was observed that both surfaces were completely covered by the apatite deposits (Fig.3b and d), which induced greater values of surface roughness (Ra). The formation of some agglomerates with globular shape and microcracks were observed in these surfaces. These microcracks could be related to the thickness of the apatite layer. Higher magnification SEM image of sample NT600 (Fig. 3b) displays a morphology typically reported for apatite coatings deposited by treatments based on solutions [35]. Furthermore, the nano-apatites plates were oriented perpendicular to the substrate surface. The higher magnification SEM image of NT800 surface shows a micro-nano- 
topography formed by micro and nano-pores and nano-plates of apatite. In addition, some dense areas were observed in these samples.

XEDS-SEM and XRD analyses confirmed the apparition of hydroxyapatite coatings on samples NT600 and NT800 (Fig. 4 and 5), which is consistent with the superficial morphology observed by SEM, and it is related to the higher bioactivity of the pre-calcified samples through the NT route. Besides, this treatment had a significant influence on the formation of the hydroxyapatite phase. The XRD peaks associated with hydroxyapatite were more clearly observed in the pattern of the specimen NT800 due to a higher crystallinity. Additionally, the XRD analysis exhibited a preferential crystalline direction of the hydroxyapatite layers as the (002) reflection at $25.7^{\circ}$ was the most intense. The effect of the temperature was also qualitatively appreciated in the intensity of the Rutile XRD peaks, the higher the temperature, the higher peak intensity (Fig. 5). It is related to the presence of a thicker layer due to an enhanced oxygen diffusion through the hydroxyapatite coating.

Tribo-mechanical analyses were focused on the studies of the roughness and scratch tests for $5 \mathrm{~N}$ loads. In the case of the sample CT800, the coating showed some damaged areas after the scratch test, so penetration and scratch curves presented different shapes. However, the measured parameters were comparable to the other samples. In the NT samples, the temperature used during the post-deposition treatment did not influence the values of surface roughness, the penetration depth of the indenter and the plastic deformation of the coatings. In addition, the coating phase composition (hydroxyapatite and/or rutile) showed influence on the tribomechanical properties of the surfaces. The rutile layers in CT600 and CT800 surfaces showed lower values of surface roughness than the hydroxyapatite layers. Also, lower penetration depth, plastic deformation and elastic recovery were observed on the CT600 surface.

The surface roughness (Ra) of the NT600 and NT800 samples showed a significant increase compared to the NT samples (pre-calcified). Note that the cellular adhesion, as well as the cellular proliferation and differentiation appear to be partly dependent on the surface roughness [36]. Besides, surface roughness can improve the bone growth and mechanical strength of the implant-bone [36].

Calcium phosphate coatings with low coating-substrate bond strength deposited by wet chemical methods on titanium have already been reported [26 - 29]. The bond strength of these coatings depends on different factors, such as, the substrate surface roughness, surface 
modification treatment and post-deposition heat treatments [18, 26, 28, 37]. The low critical loads $\left(\mathrm{L}_{\mathrm{C} 1}\right)$ of the apatite coatings on NT600 and NT800 surfaces were higher than $5 \mathrm{~N}$. This value is at least similar to that obtained by Wang et al. [38] for apatite coatings deposited by the wet chemical method on rough titanium alloy.

\section{Conclusions}

This work has investigated the effects of two pre-calcification routes (CT and NT) and the influence of the temperature during heat treatments, in particular two temperatures, $600{ }^{\circ} \mathrm{C}$ and $800{ }^{\circ} \mathrm{C}$ : these heat treatments after the apatite deposition affected the microstructure and tribomechanical properties of the specimens. Therefore, significant differences were found on the morphology, surface roughness, chemical composition and tribo-mechanical properties of specimens surfaces. In fact, nano-apatite coatings were formed only on samples pre-calcified with NT route consisting in successive treatments in $\mathrm{NaOH}$ and $\mathrm{CaCl}_{2}$ solutions. In particular, nano-apatites plates were observed by SEM on the NT600 surface; the hardness valued measured of this sample was the lowest one. Furthermore, NT800 surface showed nano-apatites with a rod shape. Considering the heat treatment temperatures, in samples treated at $800{ }^{\circ} \mathrm{C}$, rutile layers could be appreciated on the CT and NT samples. In the case of NT800 samples, the rutile layer was obtained under the apatite layer, because of oxygen diffusion through this layer. The rutile and apatite layers presented important differences in their surface roughness and tribo-mechanical properties. The rutile layers showed lower surface roughness, and in addition, greater hardness and brittleness. The scratch tests showed that after the heat treatment the nano-apatite coatings had high bond strength to the substrate.

Authors thank to ICMS (CSIC-US) (Spain) for the use of their SEM and XRD facilities. Also, the authors thank to IMRE (Cuba) for the tests performed at the Luces project facilities. This work was supported by the Junta de Andalucía-FEDER (Spain) through the Project Ref. P12-TEP-1401 and by the Ministry of Economy and Competitiveness of the State General Administration of Spain under the grant MAT2015-71284-P. The authors would like to thank the technician J. Pinto for assistance in the tests.

\section{References}

[1] A. Sola, D. Bellucci, V. Cannillo: Biotechnol Adv 34 (2016) 504. DOI:

10.1016/j.biotechadv.2015.12.013 
[2] L. Kunc`ická, R. Kocich, T.C. Lowe: Prog Mater Sci 88 (2017) 232. DOI:

10.1016/j.pmatsci.2017.04.002

[3] L.L. Guéhennec: Dent Mater (2007) 844. DOI: 10.1016/j.dental.2006.06.025

[4] G.-S. Shi, L.-F. Ren, L.-Z. Wang, H.-S. Lin, S.-B. Wang, Yong-Qing Tong: Oral Surg Oral Med Oral Pathol Oral Radiol Endod 108 (2009) 8. DOI: 10.1016/j.tripleo.2009.05.033

[5] G. Wang, S. Moya, Z. Lu, D. Gregurec, H. Zreiqat: Nanomedicine (Lond) 10 (2015) 1327. DOI: $10.2217 / \mathrm{NNM} .14 .216$

[6] Y. Su, C. Luo, Z. Zhang, H. Hermawan, D. Zhu, D. Zhu, J. Huang, Y. Liang, L.R. G. Li: J mech behav biomed mater 77 (2018) 90. DOI: 10.1016/j.jmbbm.2017.08.035

[7] J.S. Temenoff, A.G. Mikos, 2008. Biomaterials: The Intersection of Biology and Materials Science; Pearson/Prentice Hall: Upper Saddle River, NJ, USA

[8] G. Lütjering, J.C. Williams, 2004. Titanium, 2nd ed. Springer, Berlin, Germany

[9] T. Hanawa: Mater Sci Forum 512 (2006) 243. DOI:

10.4028/www.scientific.net/MSF.512.243

[10] F. Bartolomeu, M. Sampaio, O. Carvalho, E. Pinto, N. Alves, J.R. Gomes, F.S. Silva, G. Miranda: J mech behav biomed mater 69 (2017) 128. DOI: 10.1016/j.jmbbm.2017.01.004 [11] S.L. Sing, F.E. Wiria, W.Y. Yeong: Robot Cim-Int Manuf 49 (2018) 170. DOI: 10.1016/j.rcim.2017.06.006

[12] J. Kadkhodapour, H. Montazerian, A.C. Darabi, A. Zargarian, S. Schmauder: J mech behav biomed mater 70 (2017) 28. DOI: 10.1016/j.jmbbm.2016.09.018

[13] C. Guo, A. Tang, J. Matinlinna: J Adhesion Sci Technol 26 (2012) 16.

[14] R.I.M. Asri, W.S.W. Harun, M. Samykano, N.A.C. Lah, S.A.C. Ghani, F. Tarlochan, M.R. Raza: Mat Sci Eng C 77 (2017) 1261. DOI: 10.1016/j.msec.2017.04.102

[15] T. Kokubo, S. Yamaguchi: Front Bioeng Biotechnol 3 (2015) 1. DOI:

10.3389/fbioe. 2015.00176

[16] C. Gao, C. Li, C. Wang, Y. Qin, Z. Wang, F. Yang, H. Liu, F. Chang, J. Wang: J Alloys Compd 726 (2017) 1072. DOI: 10.1016/j.jallcom.2017.08.078

[17] A. Jemat, M.J. Ghazali, M. Razali, Y. Otsuka: BioMed Res Int (2015) 1. DOI: $10.1155 / 2015 / 791725$

[18] T. Kizuki, H. Takadama, T. Matsushita, T. Nakamura, T. Kokubo: Acta Biomater 6 (2010) 2836. DOI: 10.1016/j.actbio.2010.01.007

[19] W. Harun, R. Asri, J. Alias, F. Zulkifli, K. Kadirgama, S. Ghani, J. Shariffuddin: Ceram Int 44 (2018) 1250. DOI: 10.1016/j.ceramint.2017.10.162

[20] H. Qu, M. Wei: J Biomed Mater Res B 84 (2008) 436. DOI: 10.1002/jbm.b.30889 
[21] P. Jiang, J. Liang, C. Lin: Applied Surf Sci 280 (2013) 373. DOI:

10.1016/j.apsusc.2013.04.164

[22] A. Haider, S. Haider, S.S. Han, I-Y. Kang: RSC Advances 7 (2017) 7442. DOI:

$0.1039 / \mathrm{c} 6 \mathrm{ra} 26124 \mathrm{~h}$

[23] K. Shin, T. Acri, S. Geary, A.K. Salem: Tissue Eng Part A 23 (2017) 1169. DOI:

10.1089/ten.tea.2016.0556

[24] N. Ohtsu, Y. Kakuchi, T. Ohtsuki: Applied Surf Sci 445 (2017) 596. DOI:

10.1016/j.apsusc.2017.09.101

[25] W. Xia, L. Fu, H. Engqvist: Ceram Int 43 (2017) 15729. DOI:

10.1016/j.ceramint.2017.08.134

[26] X. Yang, B. Zhang, J. Lu, J. Chen, X. Zhang, Z. Gu: Applied Surf Sci (2010) 2700.

DOI: 10.1016/j.apsusc.2009.11.004

[27] X. Chen, Y. Li, P.D. Hodgson, C. Wen: Mat Sci Eng C 29 (2009) 165. DOI:

10.1016/j.msec.2008.06.004

[28] X. Wang, Y. Li, J. Lin, P.D. Hodgson, C.e. Wen: Dent Mater 24 (2008) 1549. DOI:

10.1016/j.dental.2008.03.018

[29] J. Forsgren, F. Svahn, T. Jarmar: Acta Biomater 3 (2007) 980. DOI:

10.1016/j.actbio.2007.03.006

[30] T. Kokubo: Biomater 12 (1991) 155. DOI: 10.1016/0142-9612(91)90194-F

[31] A. International, 2010. Standard test method for adhesion strength and mechanical failure modes of ceramic coatings by quantitative single point scratch testing ASTM C162405(2010). West Conshohocken, PA.

[32] T. Kokubo, S. Yamaguchi: Open Biomed Eng J 9, (Suppl 1-M2) (2015) 29.

[33] K. Lee, D. Yoo: Arch Metallurgy Mat 60 (2015) 1371. DOI: 10.1515/amm-2015-0133

[34] C. Lindahl, H. Engqvist, W. Xia: ISRN Biomaterials 2013 (2013) 1. DOI:

$10.5402 / 2013 / 205601$

[35] Y.F. Chou, W.A. Chiou, Y. Xu, J.C. Dunn, B.M. Wu: Biomaterials 25 (2004) 5323.

DOI: $10.1016 /$ j.biomaterials.2003.12.037

[36] R.A. Surmenev, M.A. Surmeneva, A.A: Ivanova. Acta Biomater 10 (2014) 557. DOI:

10.1016/j.actbio.2013.10.036

[37] C. Aparicio, D. Rodriguez, F.J. Gil: Mat Sci Eng C 31 (2011) 320. DOI:

10.1016/j.msec.2010.09.018

[38] J. Wang, P. Layrolle, M. Stigter, K. de Groot: Biomaterials 25 (2004) 583. DOI:

10.1016/S0142-9612(03)00559-3 


\section{List of table captions.}

Table 1. Sample codes and experimental design matrix.

Table 2. Compositional analyses (\% at.) by EDX-SEM.

Table 3. Surface roughness parameters (absolute values) of the studied samples. Relative error below $0.1 \%$

Table 4. Scratch parameters. 


\section{List of figures.}

Figure 1. SEM images of the cp-Ti surface at different stage of the modification treatments. (a) Polished, (b) AE treatment, (c) CT treatment and (d) NT treatment.

Figure 2. Normalized XEDS-SEM profile of the modified surfaces.

Figure 3. SEM images of samples (a) CT600, (b) NT600, (c) CT800 and (d) NT800 (common scale bar). Inset: higher magnification images of each samples with a common scale bar of $1 \mu \mathrm{m}$.

Figure 4. Normalized XEDS-SEM profile of the whole set of samples after the SCS and thermal treatments.

Figure 5. X-ray diffraction patterns of the all analyzed samples a) CT600, b) NT600, c) CT800 and d) NT800.

Figure 6. Surface roughness profile of the samples after of the SCS treatment.

Figure 7. In-situ penetration depth and elastic recovery of samples during scratch test (load 5 $\mathrm{N})$. Difference between scratch (solid curves) and the real plastic deformation associated with the scratch tests (dotted curves).

Figure 8. SEM images of micro-scratch scar on the surface of samples. (a) CT600, (b) NT600, (c) CT800 and (d) NT800 surfaces. 


\section{Tables}

Table 1. Sample codes and experimental design matrix.

\begin{tabular}{|c|c|c|}
\hline Sample & Activation treatments & Temperature $\left({ }^{\circ} \mathrm{C}\right)$ \\
\hline CT600 & AE + CT & 600 \\
\cline { 1 - 2 } CT800 & & 800 \\
\hline NT600 & AE + NT & 600 \\
\hline NT800 & & 800 \\
\hline
\end{tabular}

Table 2. Compositional analyses (\% at.) by EDX-SEM.

\begin{tabular}{|c|c|c|c|}
\hline Sample & $\mathrm{TiO}_{2}$ & $\mathrm{CaO}$ & $\mathrm{P}_{2} 0_{5}$ \\
\hline CT600 & 99 & 1 & -- \\
\hline CT800 & 100 & -- & -- \\
\hline NT600 & 87 & 7 & 6 \\
\hline NT800 & 90 & 6 & 4 \\
\hline
\end{tabular}

Table 3. Surface roughness parameters (absolute values) of the studied samples. Relative error below $0.1 \%$.

\begin{tabular}{|c|c|c|c|c|}
\hline & CT600 & NT600 & CT800 & NT800 \\
\hline $\boldsymbol{R}_{\boldsymbol{a}}(\mu \mathrm{m})$ & 0.34 & 2.33 & 0.54 & 2.68 \\
\hline $\boldsymbol{R}_{\boldsymbol{q}}(\mu \mathrm{m})$ & 1.27 & 3.04 & 1.66 & 3.19 \\
\hline $\boldsymbol{R}_{\boldsymbol{y}}(\mu \mathrm{m})$ & 6.76 & 9.10 & 7.24 & 10.07 \\
\hline $\boldsymbol{R}_{\boldsymbol{z}}(\mu \mathrm{m})$ & 0.26 & 3.46 & 6.52 & 2.69 \\
\hline
\end{tabular}

Table 4. Scratch parameters.

\begin{tabular}{|c|c|c|c|c|}
\hline & CT600 & NT600 & CT800 & NT800 \\
\hline $\mathbf{P}_{\mathbf{d}}(\mu \mathrm{m})$ & $5.5 \pm 0.9$ & $9.6 \pm 1.4$ & $89.5 \pm 2.5$ & $9.3 \pm 1.3$ \\
\hline $\mathbf{P}_{\mathbf{l}}(\mu \mathrm{m})$ & $4.0 \pm 0.8$ & $7.8 \pm 1.6$ & $87.0 \pm 1.9$ & $7.1 \pm 1.2$ \\
\hline $\boldsymbol{\varepsilon}(\mu \mathrm{m})$ & $1.5 \pm 0.8$ & $1.8 \pm 1.6$ & $2.4 \pm 2.1$ & $2.2 \pm 1.2$ \\
& & & & \\
\hline
\end{tabular}




\section{Figures}

Figure 1

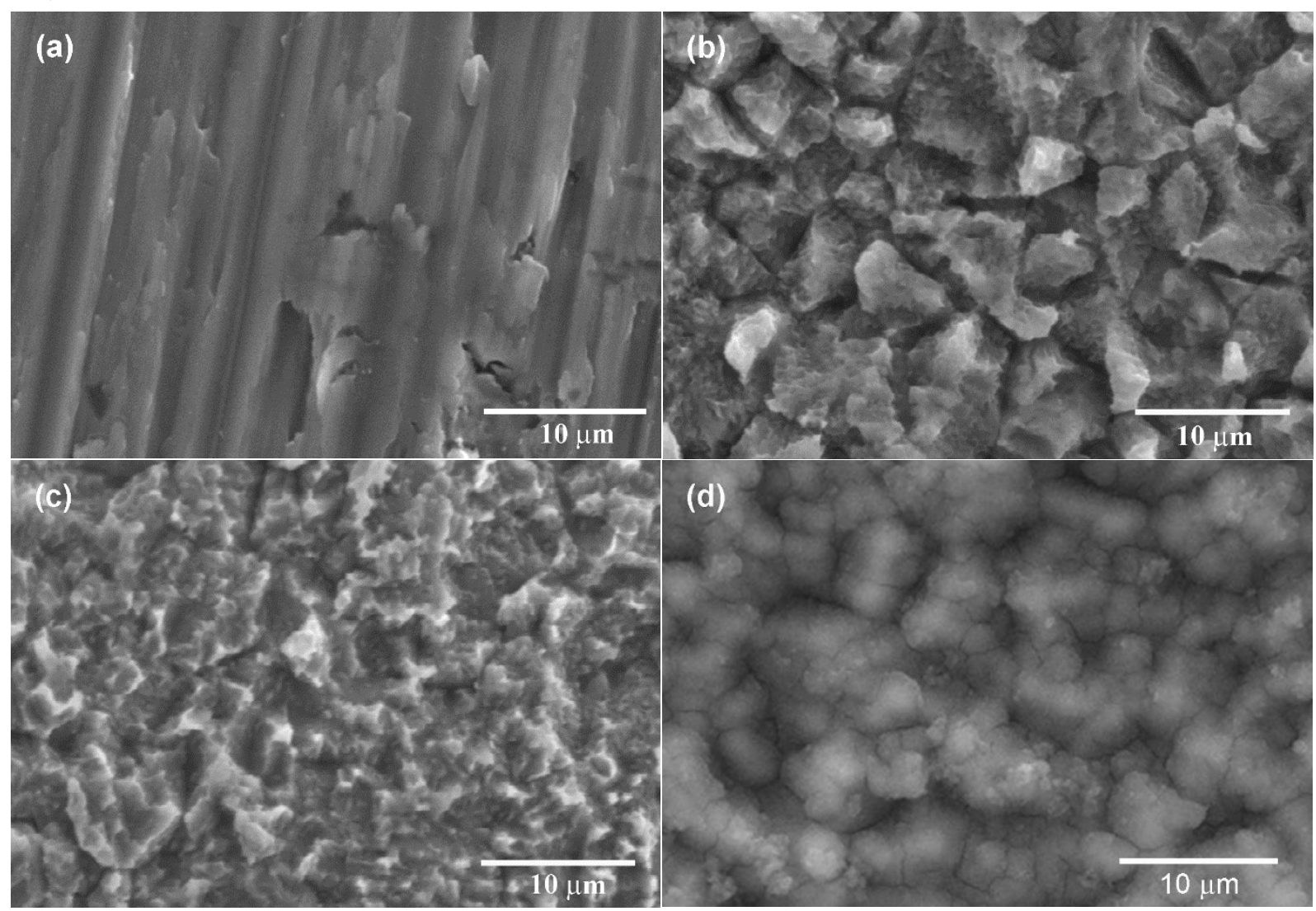

Figure 2

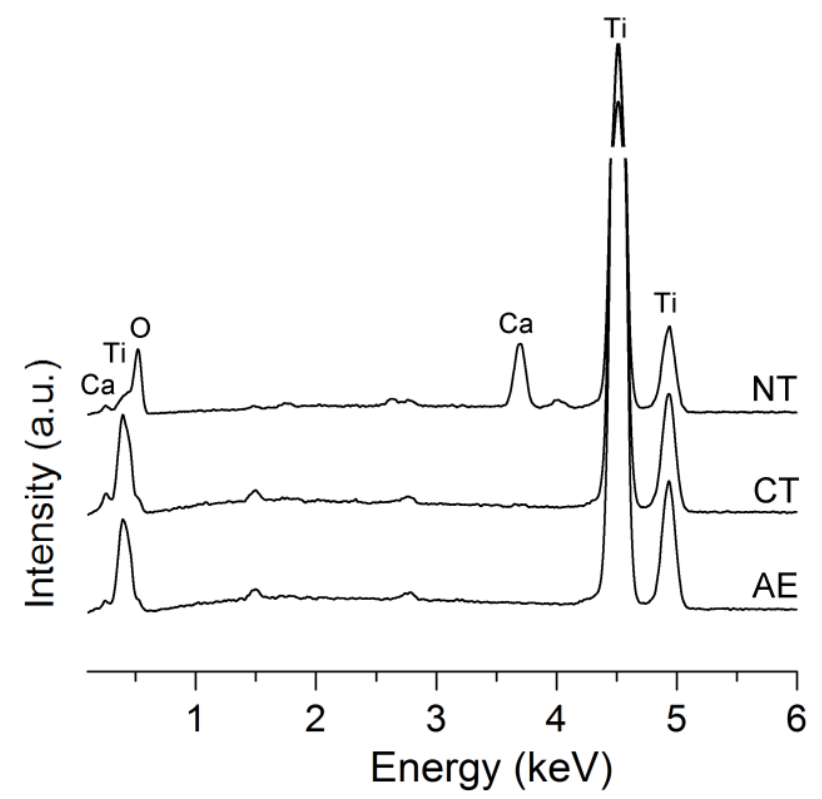


Figure 3:
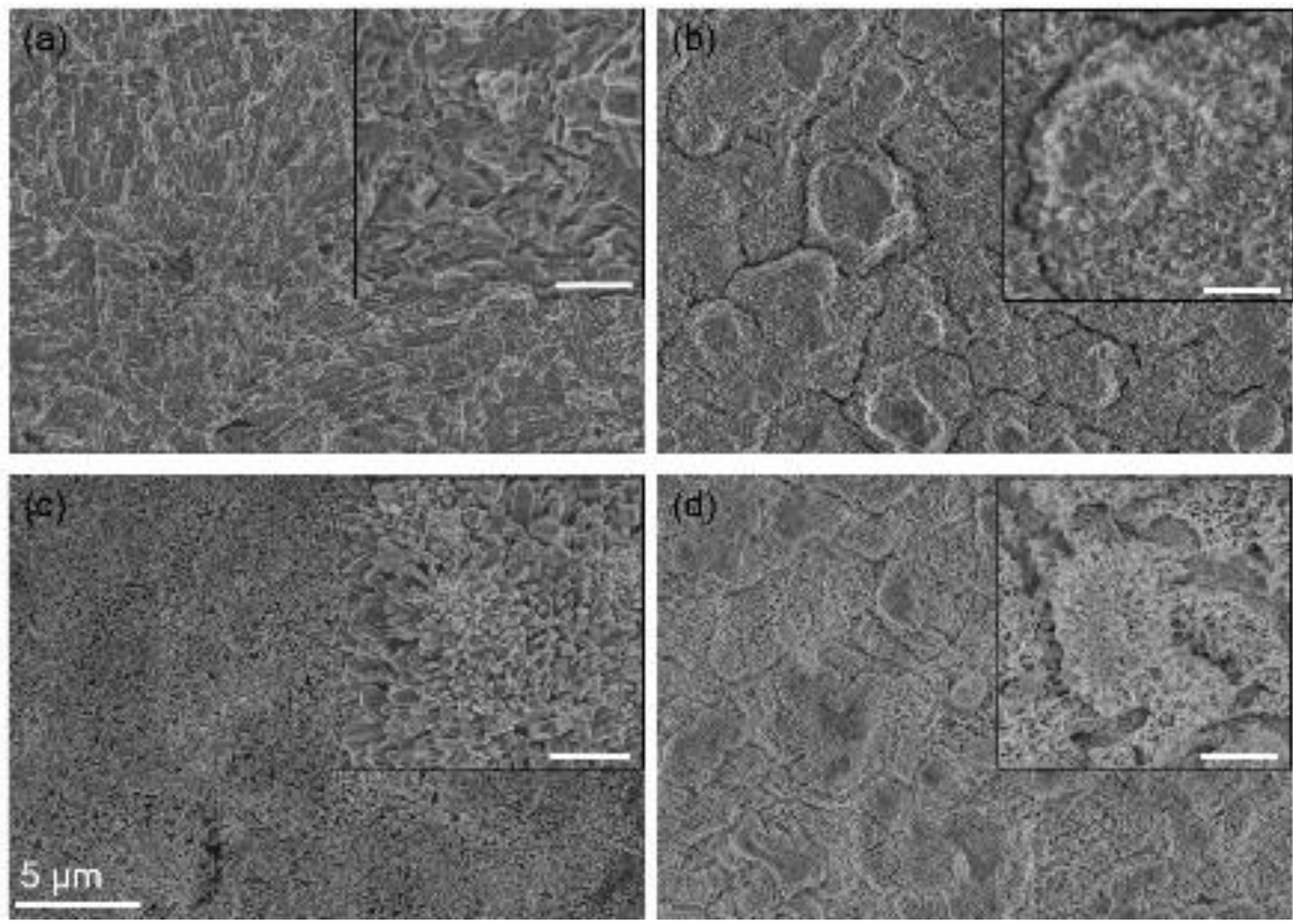

Figure 4:

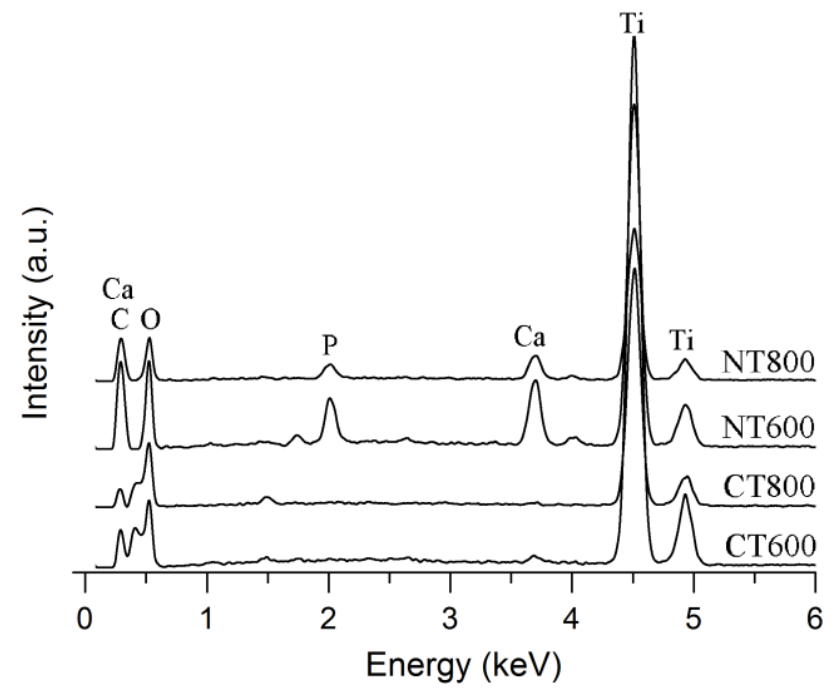


Figure 5
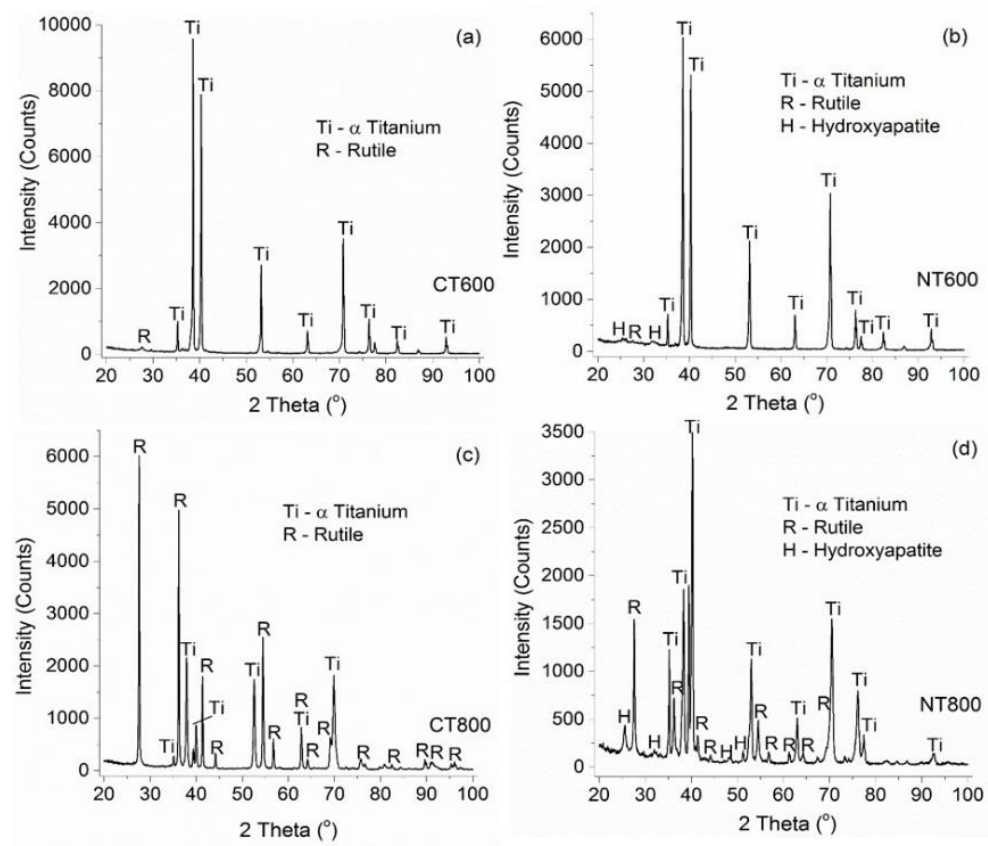

Figure 6:

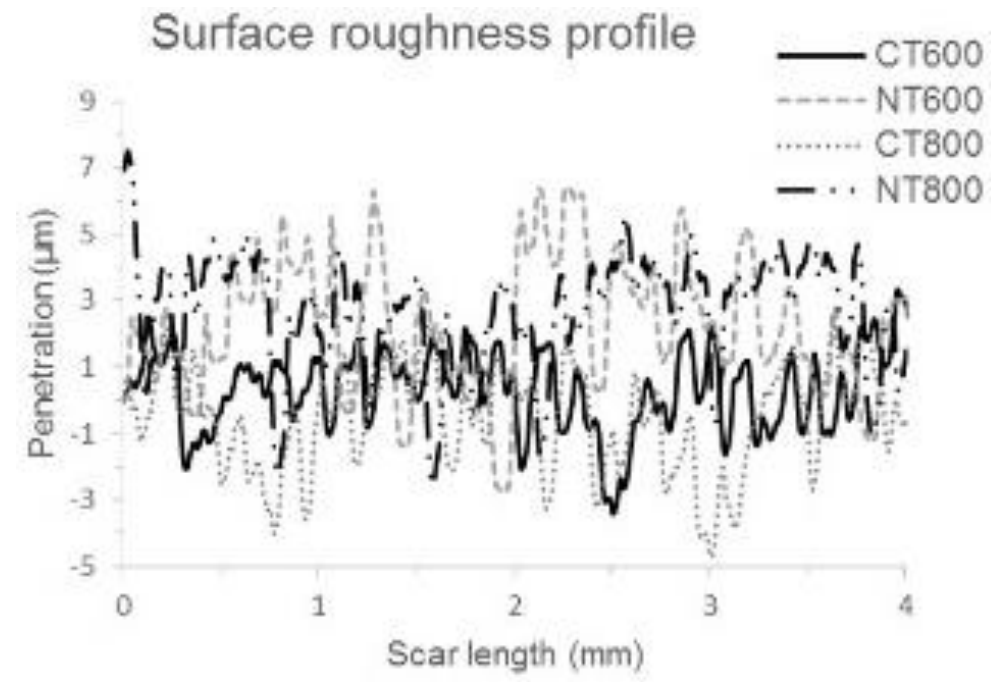


Figure 7

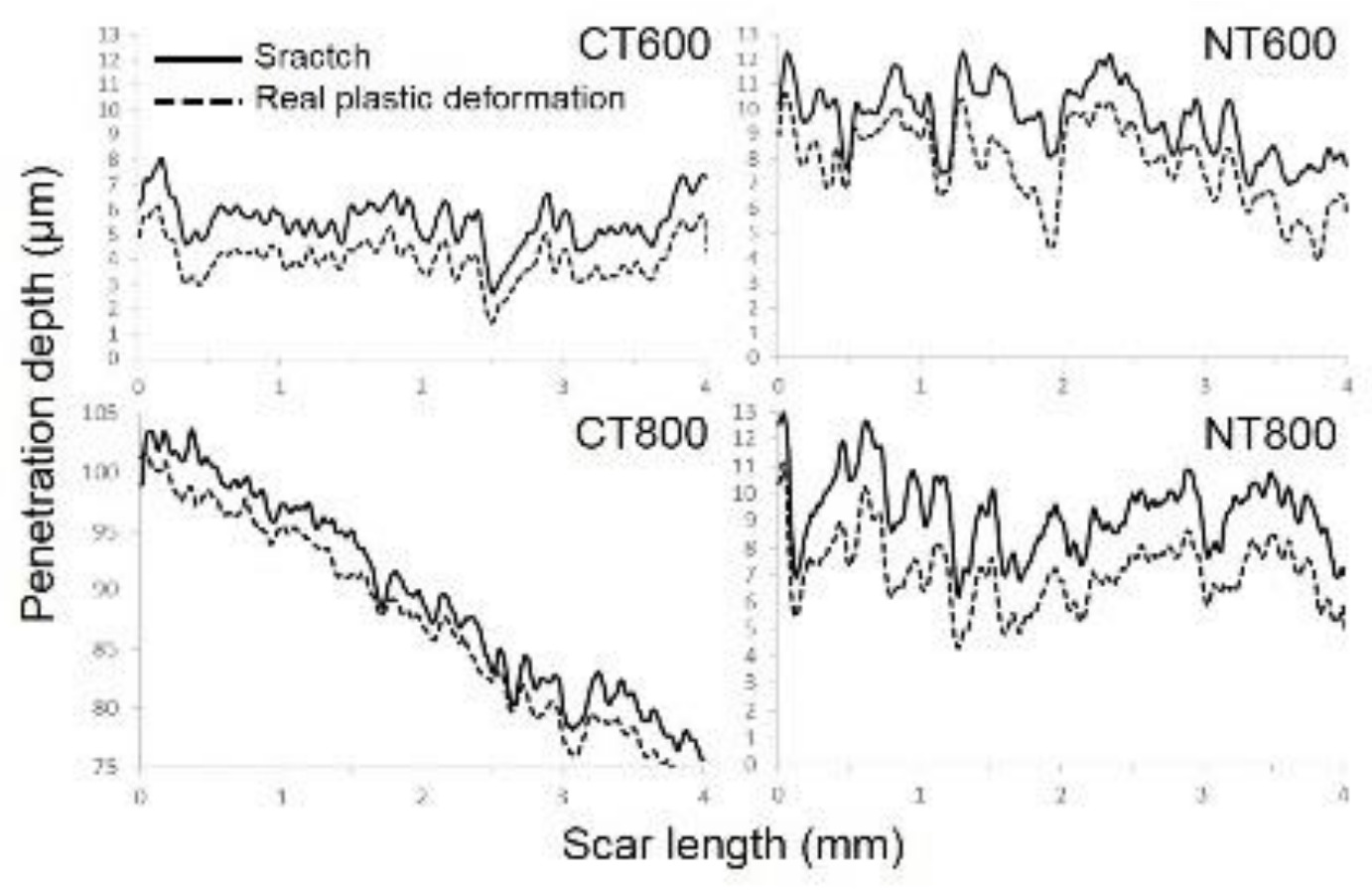

Figure 8
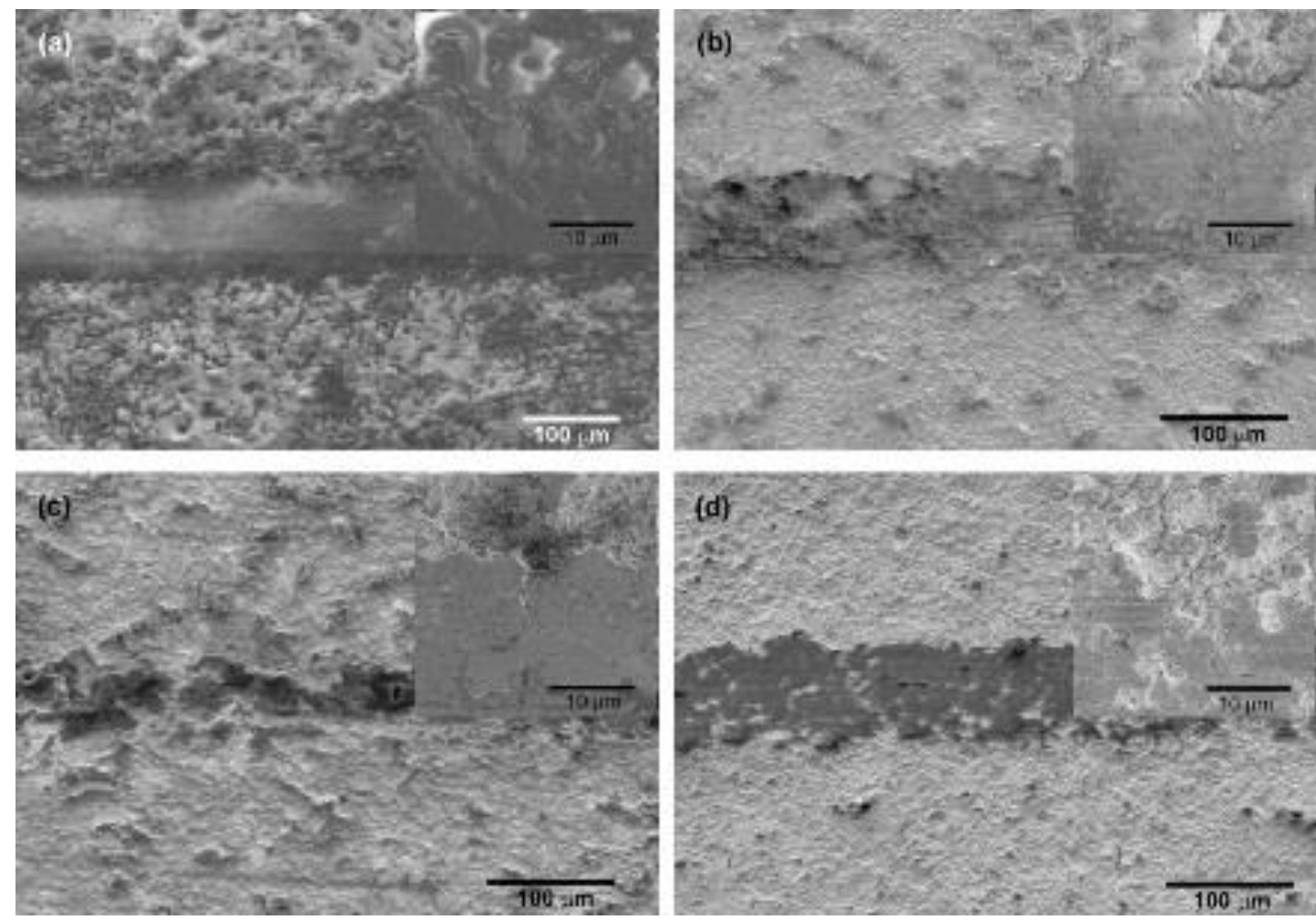